\title{
Evaluation of lysis filtration as an adjunct to conventional blood culture
}

\author{
RACHAEL CHAN, ROSEMARY MUNRO, P TOMLINSON \\ From the Bacteriology Department, Institute of Clinical Pathology and Medical Research, Westmead Hospital, \\ Sydney, New South Wales, Australia
}

SUMMARY A lysis filtration system was used in conjunction with conventional broth culture for 1112 blood cultures. The system, which entailed collection of $5 \mathrm{ml}$ of blood into bottles containing $50 \mathrm{ml}$ isotonic phosphate buffer, Tween 20, and Rhozyme with subsequent filtration using a 0.45 micron Millipore field monitor, was simple and economical to use. Positive results were obtained earlier than those obtained with conventional broth cultures, and almost twice as many fungi and yeasts were isolated. Some fastidious organisms such as Haemophilus influenzae and Streptococcus pneumoniae however, were not recovered from the lysis system, and contaminants in lysis cultures were three times as common as in conventional culture. The number of positive cultures was also adversely influenced by incubation of the blood lysis mixture overnight before filtration. We conclude that this lysis filtration system is useful as an adjunct to conventional broth culture in selected patients in cases in which filtration can be carried out soon after collection.

Concentration techniques entailing the filtration of blood components have been tried over many years to improve the yield of positive blood cultures and facilitate the rapid diagnosis of bacteraemia. The advantages of membrane filter techniques over conventional broth cultures include earlier appearance of colonies on solid media, allowing more rapid identification and antibiotic sensitivity testing; release of intracellular bacteria if cell lysing solutions are used; removal of antibacterial substances including antibiotics; the detection of mixed bacteraemias; and the possibility of measuring the extent of bacteraemia.

Early studies using membrane filtration were time consuming and difficult to perform and only $1-2 \mathrm{ml}$ of blood could be filtered. ${ }^{12}$ Other methods have been described in which individual cell constituents were cultured separately, together with filtration of plasma, ${ }^{3-5}$ but they did not entail lysis of cells with release of intracellular bacteria and were laborious to perform.

Systems using agents to lyse red cells facilitate the use of membrane techniques in a routine clinical laboratory, and the release of bacteria inside white cells by lysis will increase the likelihood of a positive culture. Some lysing solutions, however, proved to be toxic to bacteria. ${ }^{6}$

Accepted for publication 29 August 1985
Zierdt described a blood lysing solution consisting of a protease mixture (Rhozyme; Rohm and Hass, Philadelphia, USA) at $0.5 \%$ (wt/vol) with Tween 20 (polyoxyethylene sorbitan monolaurate; Sigma Chemical Co, St Louis, USA) at $\mathbf{0 . 7 \%}(\mathrm{vol} / \mathrm{vol})$ in $0.01 \mathrm{M}$ sodium phosphate buffer, $\mathrm{pH} 8 \cdot 0 .{ }^{7}$ This solution was non-toxic to a wide range of organisms tested in the laboratory, lysed blood within one hour at $37^{\circ} \mathrm{C}$, and was stable on storage at $4^{\circ} \mathrm{C}$. In addition, many organisms tested showed a growth response if left overnight in the lysed blood lysing solution mixture at $37^{\circ} \mathrm{C}$. Gill et al compared this system using filtration through a 0.45 micron $47 \mathrm{~mm}$ membrane with a commercially available lysis and centrifugation blood culture system (Isolator, DuPont Co, Wilmington, United States) and found a comparable recovery rate but a higher contamination rate in the lysis filtration system. ${ }^{8}$ As the membrane filter was incubated in brain heart infusion broth before subculture faster detection of positive cultures on solid media was obtained with the Isolator system.

We evaluated this lysis filtration system as an adjunct to a conventional broth culture. To hasten the early appearance of positive cultures on solid media we incubated the membrane filter directly on to chocolate agar plates. As many blood cultures are collected outside normal laboratory hours, we were also concerned to assess whether survival and, possibly, multiplication of bacteria would occur in blood collected 
into the lysing solution and incubated overnight before filtering.

\section{Material and methods}

\section{LYSIS MEDIUM}

The medium was prepared according to the method of Zierdt, ${ }^{7}$ modified by the use of isotonic phosphate

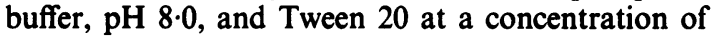
about $0 \cdot 4 \%$. Each new batch of Tween 20 was titrated for lysing activity before use in the lysis medium. Lysis medium $(50-60 \mathrm{ml})$ was aseptically dispensed by pressure filtration into bottles with screw caps containing a rubber injection port. Bottles were stored in wards at room temperature before use.

\section{COLLECTION OF SPECIMENS}

Ten millilitres of blood were aseptically collected for each blood culture. Five millilitres were inoculated into a conventional broth culture (Supplemented Pentone Broth 11, Becton Dickinson, New Jersey, United States of America) and $5 \mathrm{ml}$ into the bottle containing lysis medium. The conventional broth culture contained $45 \mathrm{ml}$ of supplemented peptone broth 11 with $0.3 \mathrm{gm} / 1$ sodium polyanetholesulfonate.

\section{PROCEDURE IN THE LABORATORY}

Lysis cultures received during normal laboratory hours were incubated at $37^{\circ} \mathrm{C}$ in a water bath for about one hour to complete lysis and were then filtered through a 0.45 micron filter (Field Monitor, Millipore, Bedford, United States of America) using negative pressure.

The membrane was rinsed with sterile physiological saline and then transferred aseptically to a chocolate blood agar plate that was incubated at $37^{\circ} \mathrm{C}$ in $5 \%$ carbon dioxide for three days. If lysis cultures were taken outside normal laboratory hours the bottles were incubated at $37^{\circ} \mathrm{C}$ and filtering delayed until the next day.

Conventional broth cultures were vented and incubated at $37^{\circ} \mathrm{C}$. Subculturing was performed when evidence of growth was observed, and routinely after 24 hours and 48 hours of incubation. Cultures were retained for at least one week before discarding. Subculture was performed on to chocolate agar in 5\% carbon dioxide, MacConkey agar aerobically, and enriched blood agar anaerobically. Negative aerobic, anaerobic, and carbon dioxide cultures were incubated for up to 48 hours. All incubation took place at $37^{\circ} \mathrm{C}$. The isolated organisms were identified by standard methods. ${ }^{9}$

All patients from whom positive cultures were obtained were assessed clinically by the Infectious Diseases Registrar. The isolated organisms were regarded as clinically important if recovered from blood cultures on more than one occasion, or if the same organism was isolated from another site from which bacteraemia could have originated, and if the patient had a clinical illness and response to antibiotics consistent with recovery of that organism from blood cultures. Organisms were regarded as contaminants if isolated once only with no substantiating clinical or bacteriological evidence of infection.

\section{Results}

A total of 1112 blood cultures were collected using a conventional broth culture and a lysis culture in parallel. Eighty three cultures positive by conventional culture and lysis filtration were obtained; 17 were negative by lysis filtration and positive by conventional culture; 980 cultures were negative by both methods; and 32 were positive by lysis filtration and negative by conventional culture. A total of 115 blood cultures were positive by at least one of the two techniques.

Nine organisms isolated by lysis filtration were regarded as contaminants: four Staphylococcus epidermidis; one each of Staphylococcus aureus; Bacillus $s p ;$ Micrococcus sp; Moraxella nonliquefaciens, and Acinetobacter calcoaceticus. Three organisms isolated from conventional culture were regarded as contaminants; one each of $S$ epidermidis; Flavobacterium

Table 1 Organisms isolated from blood cultures by lysis filtration and conventional broth culture

\begin{tabular}{|c|c|c|}
\hline \multirow[t]{2}{*}{ Organism } & \multicolumn{2}{|l|}{ No of Isolates } \\
\hline & Lysis filtration & $\begin{array}{l}\text { Conventional } \\
\text { culture }\end{array}$ \\
\hline $\begin{array}{l}\text { Gram positive: } \\
\text { Staphylococcus aureus } \\
\text { Staphylococcus epidermidis } \\
\text { Streptococcus faecalis } \\
\text { Streptococcus pneumoniae } \\
\text { Streptococcus mitis } \\
\text { Streptococcus milleri } \\
\text { Streptococcus sp } \\
\text { Listeria monocytogenes } \\
\text { Micrococcus sp } \\
\text { Bacillus sp } \\
\text { Gram negative: } \\
\text { Enterobacteriaceae } \\
\text { Pseudomonas aeruginosa } \\
\text { Pseudomonas maltophilia } \\
\text { Aeromonas sp } \\
\text { Flavobacterium sp } \\
\text { Haemophilus influenzae } \\
\text { Moraxella nonliquefaciens } \\
\text { Acinetobacter calcoaceticus } \\
\text { Achromobacter xylosoxidans } \\
\text { Total } \\
\text { Yeasts and Fungi: } \\
\text { Candida albicans } \\
\text { Candida tropicalis } \\
\text { Trichosporan cutaneum } \\
\text { Aspergillus fumigatus } \\
\text { Total }\end{array}$ & $\begin{array}{r}2 \\
2 \\
4 \\
1 \\
1 \\
40 \\
6 \\
4 \\
4 \\
2 \\
1 \\
1 \\
1 \\
108 \\
\\
6 \\
2 \\
5 \\
1 \\
14\end{array}$ & $\begin{array}{r}16 \\
16 \\
5 \\
2 \\
2 \\
2 \\
2 \\
3\end{array}$ \\
\hline
\end{tabular}

Four cultures with multiple isolates were obtained. 
Table 2 Duration of incubation before culture positivity in paired lysis filtration and conventional blood cultures

\begin{tabular}{lll}
\hline $\begin{array}{l}\text { Duration of incubation } \\
\text { from collection }\end{array}$ & $\begin{array}{l}\text { Lysis filtration } \\
\text { culture }\end{array}$ & $\begin{array}{l}\text { Conventional } \\
\text { culture }\end{array}$ \\
\hline $18-24$ hours & 74 & $28^{*}$ \\
48 hours & 7 & $39 \dagger$ \\
3 days & 1 & 11 \\
7 days & & 3 \\
$>7$ days & & 1 \\
\hline Total & 82 & 82
\end{tabular}

* Conventional culture positive by Gram stain of turbid broth. †Conventional culture positive by subculture on to solid media after 24 hours incubation of the broth culture.

One culture positive by both methods after 72 hours of incubation was excluded as a contaminant.

There were significantly more positive cultures obtained by lysis filtration after 18-24 hours than with conventional culture ( $p<0.001$, difference of proportions).

$s p$; and $S$ aureus). Table 1 shows the range of organisms isolated using both systems. The number of positive cultures from each system was similar. For individual organisms, numbers isolated were too small for statistical comparison.

Table 2 shows the duration of incubation before a positive culture was detected by either method. Lysis filtration detected significantly more positive cultures after 18-24 hours of incubation than did the conventional broth culture $(p<0.001)$. Table 3 shows the effect of overnight incubation at $37^{\circ} \mathrm{C}$ of the blood lysing solution before filtration on the number of positive cultures obtained. Significantly fewer positive cultures were obtained after overnight incubation ( $p$ $<0.001)$.

\section{Discussion}

The use of a lysis filtration system had several advantages over conventional culture for detecting bacteraemia. Considerably more cultures were positive earlier than with the conventional broth culture, and the appearance of colonies on the filter 24 hours before they could be cultured on solid media from conventional broth culture assisted in early identification and accurate antibiotic sensitivity testing.

Table 3 Effect of overnight incubation at $37^{\circ} \mathrm{C}$ of blood lysis medium before filtration

\begin{tabular}{lll}
\hline & No of blood cultures \\
\cline { 2 - 3 } & $\begin{array}{l}\text { Filtered the day of } \\
\text { collection }(n=471)\end{array}$ & $\begin{array}{l}\text { Incubation overnight before } \\
\text { filtration }(n=641)\end{array}$ \\
\hline Positive & 58 & 57 \\
Negative & 413 & 584
\end{tabular}

Significantly more positive cultures were obtained when the blood and lysis medium was filtered on the day of collection than when incubation overnight occurred before filtration $(p<0.001$, difference of proportions).
The lysis filtration system waś more successful than the conventional broth culture for the recovery of yeasts. Some fastidious organisms, however, such as Haemophilus influenzae and Streptococcus pneumoniae were not recovered from the lysis filtration system. Although the numbers of isolations of Streptococci and Haemophilus influenzae from the two systems were too small for statistical comparison, survival experiments we conducted suggested that the lysing solution was toxic for these organisms after four hours of incubation. The toxic component of the lysing solution was Tween 20 , and further investigation is necessary to ascertain whether this inimical effect can be circumvented.

The technique is suitable for a routine clinical laboratory as the time required for lysis and filtration is not excessive. The cost of a lysis filtration culture in addition to a conventional culture is much less than other commercially available concentration techniques such as lysis centrifugation. Due to the small size of the filter and the risk of contamination associated with dividing it, however, we restricted culture of the membrane to one medium suitable for aerobic and facultative anaerobic organisms alone. Even so, contamination with the lysis filtration system was three times higher (accounting for $6 \%$ of the total positive isolates obtained) than when conventional cultures were used ( $2 \%$ of the total positive isolates).

As overnight incubation at $37^{\circ} \mathrm{C}$ of the blood lysing solution did appreciably affect the number of positive cultures obtained the method is not optimal for cultures collected outside normal laboratory hours. A concentration technique is a desirable feature to incorporate into blood culture procedures. It should, however, be simple to perform and economical. This technique has similar disadvantages to other concentration techniques, - namely, a higher contamination rate as a result of being an open system and its inability to propagate some fastidious organisms. The system can offer advantages, however, when used in addition to a conventional broth culture. As the cost of equipment and technical time for processing are not excessive its use as an adjunct to a conventional broth culture suitable for isolation of anaerobes and other fastidious organisms is feasible for selected patients, especially when fungal septicaemia is a possibility, or when there is a high probability of bacteraemia.

We thank Millipore Corporation, Australia for supplying field monitors for this trial and Mrs Marian Sonnberg for valuable clerical help.

\section{References}

${ }^{1}$ Braun W, Kelsh J. Improved method for cultivation of Brucella from the blood. Proc Soc Exp Biol Med 1954;85:154-5. 
${ }^{2}$ Tidwell WL, Gee LL. Use of membrane filter in blood cultures. Proc Soc Exp Biol Med 1955;88:561-3.

${ }^{3}$ Winn WR, White ML, Carter WT, Miller AB, Finegold SM. Rapid diagnosis of bacteraemia with quantitative differentialmembrane filtration culture. JAMA 1966;197:539-48.

${ }^{4}$ Finegold SM, White ML, Ziement I, Winn WR. Rapid diagnosis of bacteraemia. Appl Microbiol 1969;18:458-63.

${ }^{5}$ Kozub WR, Kirkham WR, Chatman CE, Pribor HC. A practical blood culturing method employing dilution and filtration. $\mathrm{Am} \mathrm{J}$ Clin Pathol 1969;52:105-13.

${ }^{6}$ Farmer SG, Komorowski RA. Evaluation of the Sterifil lysisfiltration blood culture system. Appl Microbiol 1972;23:500-4.

${ }^{7}$ Zierdt $\mathrm{CH}$. Blood-lysing solution nontoxic to pathogenic bacteria.
J Clin Microbiol 1982;15:172-4.

${ }^{8}$ Gill VJ, Zierdt CH, Wu TC, Stock F, Pizzo PA, MacLowry JD. Comparison of lysis-centrifugation with lysis filtration and conventional unvented bottles for blood cultures. J Clin Microbiol 1984;20:927-32.

${ }^{9}$ Cowan ST, Steel KJ. Manual for the identification of medical bacteria. 2nd ed. Cambridge: Cambridge University Press, 1974.

Requests for reprints to: Mrs $\mathbf{R}$ Chan, Bacteriology Department, Institute of Clinical Pathology and Medical $\vec{\circ}$ Research, Westmead Hospital, NSW, Australia 2145. 